\section{(- OPEN ACCESS}

\title{
In vivo bioassay to test the pathogenicity of missense human AIP variants
}

\author{
Elena Daniela Aflorei, ${ }_{1}^{1}$ Benjamin Klapholz, ${ }^{2}$ Chenghao Chen, ${ }_{1}^{3}$ Serban Radian, ${ }_{1}^{1,4}$ \\ Anca Neluta Dragu, ${ }^{1,3}$ Nina Moderau, ${ }^{5}$ Chrisostomos Prodromou, ${ }^{6}$ Paulo $S$ Ribeiro, ${ }^{5}$ \\ Ralf Stanewsky, ${ }^{3,7}$ Márta Korbonits ${ }^{1}$
}

\begin{abstract}
- Additional material is
published online only. To view please visit the journal online (http://dx.doi.org/10.1136/ jmedgenet-2017-105191)
\end{abstract}

${ }^{1}$ Centre for Endocrinology, Barts and the London School of Medicine, Queen Mary University of London, London, UK

2Department of Physiology, Development and Neuroscience, University of Cambridge, Cambridge, UK

${ }^{3}$ Department of Cell and Developmental Biology, Division of Biosciences, Faculty of Life Sciences, University College London, London, UK ${ }^{4}$ Department of Endocrinology, C.I. Parhon National Institute of Endocrinology, Carol Davila University of Medicine and Pharmacy, Bucharest, Romania ${ }^{5}$ Protein Dynamics and Cell Signalling Laboratory, Centre for Tumour Biology, Barts Cancer Institute, Queen Mary University of London, London, UK

${ }^{6}$ Genome Damage and Stability Centre, University of Sussex, Brighton, UK Institute of Neuro- and Behavioural Biology, Westfälische Wilhelms University, Münster, Germany

\section{Correspondence to} Professor Márta Korbonits, Department of Endocrinology, Barts and the London School of Medicine, Queen Mary University of London, London EC1M 6BQ, UK; m.korbonits@ qmul.ac.uk

Received 1 December 2017 Revised 23 February 2018 Accepted 1 March 2018 Published Online First 9 April 2018

\section{Check for updates}

To cite: Aflorei ED,

Klapholz B, Chen C, et al.

$J$ Med Genet

2018:55:522-529.

\section{ABSTRACT}

Background Heterozygous germline loss-of-function mutations in the aryl hydrocarbon receptor-interacting protein gene (AIP) predispose to childhood-onset pituitary tumours. The pathogenicity of missense variants may pose difficulties for genetic counselling and family follow-up.

Objective To develop an in vivo system to test the pathogenicity of human AIP mutations using the fruit fly Drosophila melanogaster.

Methods We generated a null mutant of the Drosophila AIP orthologue, CG1847, a gene located on the Xchromosome, which displayed lethality at larval stage in hemizygous knockout male mutants (CG1847 $7^{\text {exon1_3}}{ }^{3}$. We tested human missense variants of 'unknown significance', with 'pathogenic' variants as positive control.

Results We found that human AIP can functionally substitute for CG1847, as heterologous overexpression of human AIP rescued male CG1847 $7^{\text {exon1_3 }}$ lethality, while a truncated version of AIP did not restore viability. Flies harbouring patientspecific missense AIP variants (p.C238Y, p.I13N, p.W73R and p.G272D) failed to rescue CG1847 $7^{\text {exon1_3 }}$ mutants, while seven variants (p.R16H, p.Q164R, p.E293V, p.A299V, p.R304Q, p.R314W and p.R325Q) showed rescue, supporting a non-pathogenic role for these latter variants corresponding to prevalence and clinical data.

Conclusion Our in vivo model represents a valuable tool to characterise putative disease-causing human AIP variants and assist the genetic counselling and management of families carrying AIP variants.

\section{INTRODUCTION}

Pituitary adenomas arise from hormone-secreting cells of the anterior pituitary gland. The presenting symptoms are due to either excess or deficiency of pituitary hormones or local space-occupying effects. Loss-of-function mutations in the aryl hydrocarbon receptor-interacting protein gene $(A I P)$ predispose to an autosomal dominant disorder with incomplete penetrance $(20 \%-23 \%)$ associated usually with growth hormone-secreting pituitary adenomas leading to acromegaly or gigantism. ${ }^{1-3}$ To date, more than 100 different AIP variants have been identified, with the majority $(75 \%)$ resulting in a missing or truncated AIP protein. ${ }^{23} \mathrm{~A}$ change in amino acid sequence due to missense variants could affect protein folding and stability ${ }^{4}$ and may alter the availability of protein-protein interaction sites. The C-terminus of AIP includes conserved tetratricopeptide repeat (TPR) domains, and alterations in key amino acids are known to disrupt secondary structure, leading to unstable proteins. ${ }^{5-7}$ While pathogenicity is beyond doubt for the truncating mutations, establishment of pathogenicity for missense variants can be challenging, posing therefore a key question for clinical genetic counselling and decision making. ${ }^{8}$

The strategies employed to establish pathogenicity for heterozygous tumour suppressor genes, such as AIP, include: allele frequency in the general population, loss of the wild-type (wt) allele in the tumour (loss of heterozygosity $(\mathrm{LOH}))$, in silico prediction pipelines, ${ }^{9}$ in vitro functional studies and evaluation of variant segregation with the phenotype in large pedigrees. ${ }^{10}$ $\mathrm{LOH}$ analysis of tumourous tissue has also been exploited to determine the pathogenic role of AIP variants, ${ }^{11} 12$ and AIP immunostaining is significantly reduced in the majority but not in all patients carrying AIP mutations. ${ }^{13-15}$ In vitro functional studies have also been employed to evaluate the protein stability of AIP variants, ${ }^{4}$ their effect on cell proliferation ${ }^{13}$ and their interaction with PDE4A5 $5^{13}{ }^{16}$ and RET, ${ }^{17}$ but these assessments are necessarily indirect.

However, the in vivo consequences of AIP missense variants have never been investigated. We aimed to develop an in vivo strategy to help determine the pathogenicity of missense AIP variants.

\section{MATERIALS AND METHODS}

Fly stocks and genetics

The Drosophila melanogaster strains used in this study: $w^{\text {iso }}$ (gift from Nic Tapon, London, UK), $y w ; B l / C y O$ (Lindsley and Zimm), ${ }^{18} w^{*} P\{E P\}$ CG1847 ${ }^{G 1839}$ (Bloomington Drosophila Stock Center: Stock ID: 32600), ${ }^{19} y w ; K i, p p, \Delta 2-3$, $P\{$ CaryP $\} a t t P 40$ embryos (BestGene Inc, California, USA) and yw; Act-Gal4/CyO.

\section{Drosophila husbandry}

Fly crosses were maintained at $25^{\circ} \mathrm{C}$. For counting, the rescued males crosses were flipped every 9-10 days to prevent the mix of individual flies from different generations. 


\section{Generation of mutant CG1847 flies: imprecise excision screen}

The CG1847 gene was mutated by P-element transposase-mediated deletion of genomic DNA. For this, a fly line was obtained, in which a P-element is inserted within the 5'UTR of CG1847: ${ }^{*} \mathrm{P}\{\mathrm{EP}\}$ CG1847 ${ }^{\mathrm{G} 1839}$ (Bloomington Drosophila Stock Center). ${ }^{20}$ Females homozygous for the CG1847 mutation are not viable, while heterozygous mutant females develop normally. The resulting stocks were screened by PCR, and the putative mutants were identified via Sanger sequencing. Sequence chromatograms were visualised and analysed using the BioEdit Sequence Alignment Editor software (http://www.mbio.ncsu.edu/bioedit/bioedit.html) (Ibis Biosciences, Carlsbad, California, USA).

\section{Rescue of CG1847 function}

A genomic rescue construct containing the regulatory and coding regions of CG1847 (2763 bp) was generated, cloned into the pW@ RpA vector (kindly provided by Professor Nick Brown's laboratory, Cambridge, UK, details available on request).

To obtain the genomic rescue construct for hAIPwt, the AIP cDNA insert (1001bp) was amplified from a pcDNA3-Myc-AIPwt vector. ${ }^{13}$ To obtain the genomic rescue construct of truncated AIP, the last $86 \mathrm{bp}$ encoding for the seventh alpha helix were deleted. Transgenic lines for 11 different hAIP mutations (p.I13N, p.R16H, p.W73R, p.Q164R, p.C238Y, p.G272D, p.E293V p.A299V, p.R304Q, p.R314W and p.R325Q) were also generated. Mutagenic primers were designed using the Stratagene's QuickChange Primer Design program at www.stratagene.com/qcprimerdesign. The QuickChange XL Site-Directed Mutagenesis kit (Agilent Technologies) was used, and mutagenesis was done according to standard recommended procedure.

All transgenic lines were generated by injecting the rescue constructs into Drosophila $y^{1} w^{67 c 23} ; P\{$ CaryP $\}$ attP40 embryos, which enabled the generation of transgenic stocks with constructs on chromosome 2. These transgenic fruit flies stocks were balanced over the balancer chromosome $\mathrm{CyO}$. For males resulting from the rescue crosses, the hAIP transgene (online supplementary figure 4B,C: middle panels) was detected using primers against human AIP cDNA. In addition, the presence of Y chromosome (bottom panels) was detected using a set of primers for the Ppr-Y gene.

\section{Statistical analysis}

Experimental data sets were analysed in JMP (SAS institute). Statistical comparisons were analysed with one-way analysis of variance followed by a Tukey-Kramer test. Data are presented as mean \pm SEM. A value of $\mathrm{P}<0.05$ was considered to be statistically significant.

\section{Western blotting analyses}

The different UAS (Upstream Activation Sequence) insertions for the human AIP were confirmed to drive protein expression in combination with the actin-GAL4 using specific commercially available antibody. The Western blots were incubated overnight, at $4^{\circ} \mathrm{C}$, with primary antibody anti-AIP/ARA9 Mouse Monoclonal $^{21}$ (Novus Biologicals) at a dilution of 1:1000. AntiBeta Tubulin, Mouse monoclonal (E7 Developmental Studies Hybridoma Bank $)^{22}$ was used as a loading control at a dilution of 1:15 000. Secondary antibody IRDye 680 LT Goat anti-Mouse IgM (LI-COR Biotechnology) was used at a concentration of 1:1000. Odyssey Infrared Imaging System (LI-COR) was used for image acquisition. Results are representative of four independent western blot analyses from two independent experimental replicates.

\section{RESULTS}

\section{Characterisation of the Drosophila orthologue of human AIP}

The D. melanogaster gene CG1847 (NM_132530.4) ${ }^{23}$ is the fruit fly's single orthologue of human AIP. This three-exon gene is located on chromosome $\mathrm{X}$ at position 10F2, base pair (bp) 11869170 to 11871168 (Drosophila genome release August 2014). As it is located on the $X$ chromosome, male flies will have only one copy of this gene.

CG1847 is a previously uncharacterised Drosophila gene, and no phenotypic fruit fly data are available in public databases. Protein alignment of CG1847 (FBtr0073567) and human AIP (hAIP, ENST00000279146) was performed by Clustal Omega ${ }^{24}$ and revealed a shared overall identity of $38 \%$ (Figure 1A). The three-dimensional theoretical model of CG1847 (Figure 1B) revealed a protein structure that closely resembles the published AIP protein structure, with a typical N-terminal peptidyl-prolyl cis-trans isomerases (PPIase)-like domain ${ }^{25}$ and the C-terminal TPR domains. ${ }^{26}$
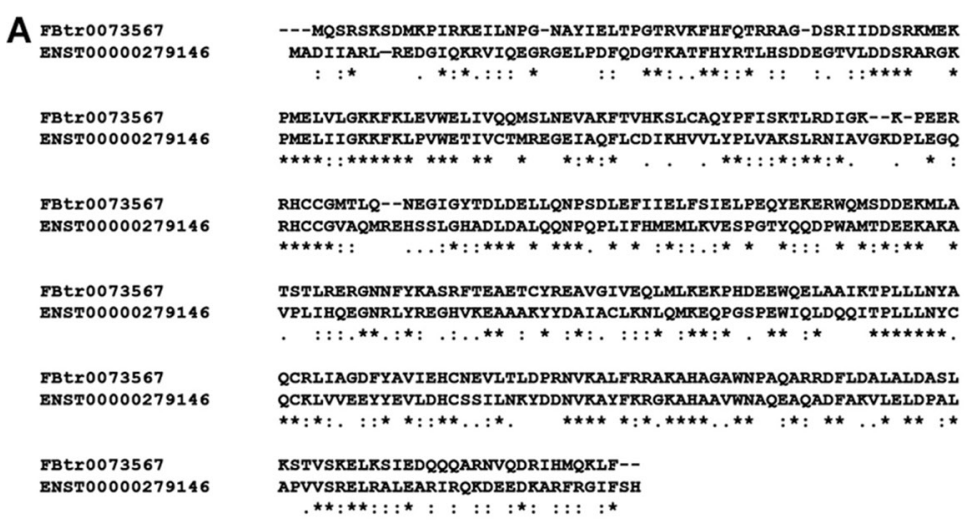

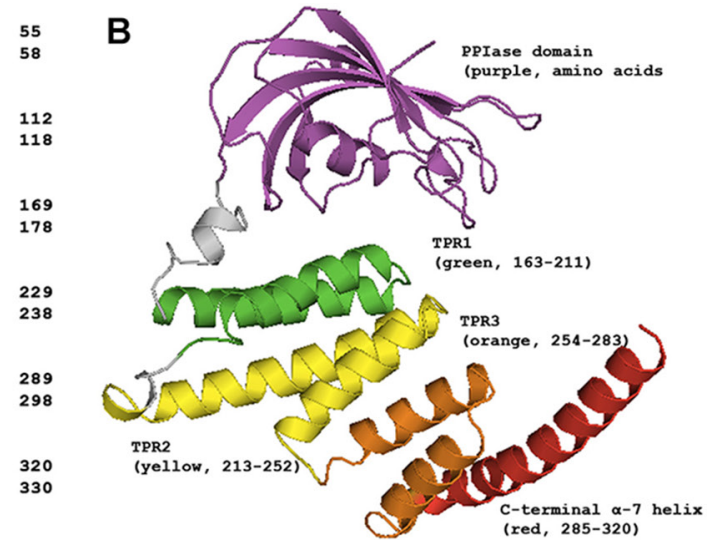

Figure 1 Comparison of Drosophila CG1847 and human AIP proteins. (A) The human and Drosophila proteins are similar; they share 120 identical amino acids, 80 strongly conserved and 34 weakly conserved amino acids. Stars indicate identity, and colons and dots indicate high and low similarity amino-acids, respectively. (B) A three-dimensional predicted model of CG1847 indicates that the Drosophila protein has a similar structure to its human orthologue, with an N-terminal PPlase domain, three pairs of conserved antiparallel alpha-helices forming the tetratricopeptide repeat domains (TPRs) and the final extended $\alpha$-helix, $\alpha-7$. AIP, aryl hydrocarbon receptor-interacting protein gene. 
A

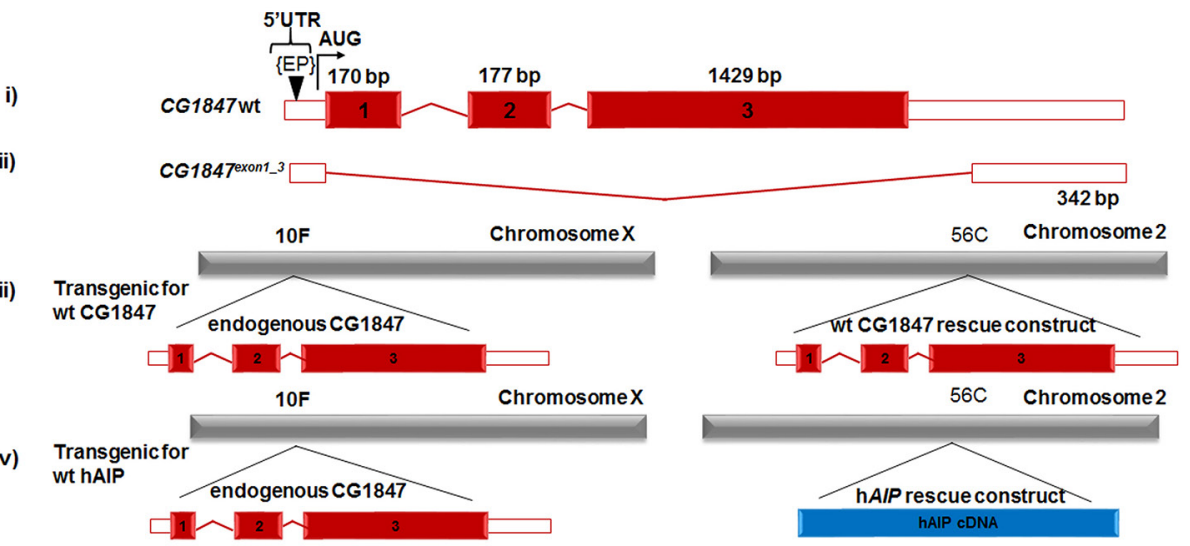

B

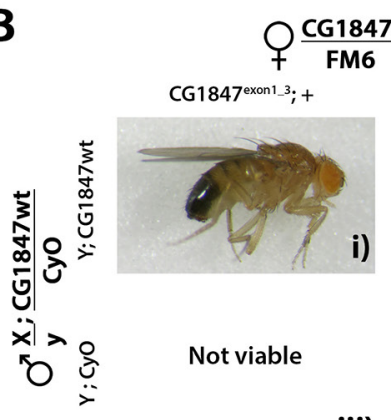

iii)

\section{i)}

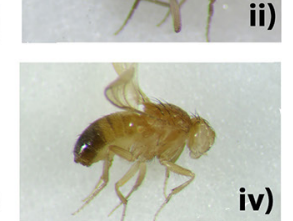

C

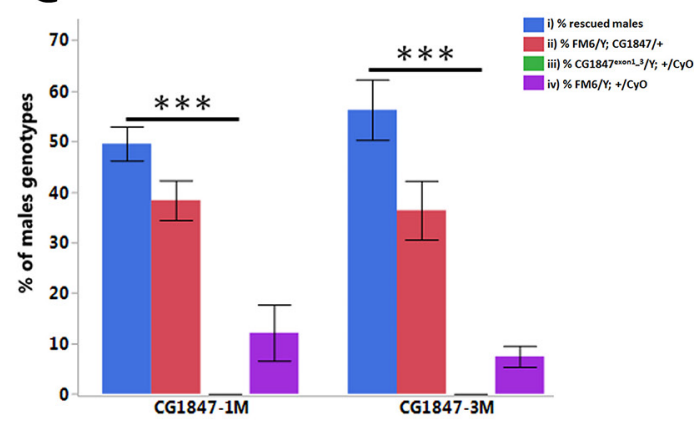

Figure 2 The lethality of CG1847 mutants can be rescued by expression of wild-type (wt) CG1847 under the control of its own promoter. (A) Schematic

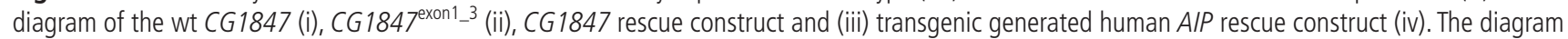
represent the mRNA, with red boxes representing coding region and white boxes representing $5^{\prime}$ and $3^{\prime}$ untranslated regions. (ii) The CG1847 mutant was generated by imprecise P-element excision of P-CG1847 ${ }^{G 1839}$ (EP in the figure). (iii) Schematic representation of transgenic animals with genomic rescue construct containing the regulatory and coding regions of CG1847 inserted on the second chromosome. (iv) Schematic representation of transgenic animals with the AIP CDNA rescue construct inserted on the second chromosome. (B) Transgenic males carrying the CG1847 genomic rescue construct and balanced over CyO were crossed to the CG1847 $7^{\text {exon } 133}$ heterozygous females and examined for their ability to rescue male lethality. Segregation of alleles and the possible combinations are shown in the lateral panels. Panel (i): male carrying the mutant CG1847 allele inherited from their mothers rescued by the wt CG1847 allele on the second chromosome. Panel (iii): males are not viable as they carry the CG1847 mutant allele and lack the genomic rescue construct from the paternal chromosome 2. Panels (ii) and (iv) depict male progeny lacking the CG1847 mutation. (C) Statistical analysis of rescue experiments with the CG1847 genomic rescue construct $(n=4)$. The associated letters (panels $i-i v)$ correspond to the phenotypes depicted in Figure 2B. $X$-axis labels CG1847-1M and CG1847-3M represent two different transgenic stocks carrying the rescue construct. Error bars represent SE of the mean. Asterisks indicate statistical significance as determined by Student's t-test ( $\left.{ }^{* *} \mathrm{P}<0.01\right)$. AlP, aryl hydrocarbon receptor-interacting protein gene; bp, base pairs.

\section{CG1847 is an essential gene and its loss results in early lethality}

We used imprecise P-element excision ${ }^{27}$ to generate a loss-offunction mutations in CG1847 (Figure 2A). One of the resulting lines harboured an excision of $2511 \mathrm{bp}$ covering all three exons (CG1847 $7^{\text {exon1_3 }}$, Figure 2A-ii). The deletion did not extend into the neighbouring genes CG2025 and CG11802, positioned $279 \mathrm{bp}$ and 129 bp downstream of the CG1847 5' and 3' UTR regions, respectively. CG1847 is located on the X chromosome, and no viable hemizygous males were observed carrying this mutation. Because heterozygous females were normal, viable and fertile, this suggests that complete loss of CG1847 leads to lethality, similarly to mouse knockout models. $^{28} 29$

To demonstrate that lethality of CG1847 exon1 $33^{3}$ is solely due to the deletion of CG1847 coding sequence and not caused by additional mutations generated by the imprecise excision, transgenic flies carrying a genomic rescue construct on chromosome 2, containing the wt regulatory and coding regions of CG1847 (Figure 2A-iii), were generated and injected into Drosophila embryos (BestGene). Transgenic male flies were crossed with heterozygous CG1847 ${ }^{\text {exon1_3 }}$ mutant females (Figure 2B) to study the ability of the wt CG1847 rescue construct to reverse the lethality of CG1847 $7^{\text {exon1_3 }}$ males. Hemizygous mutant CG1847 $7^{\text {exon13 } 3}$ males expressing the wt CG1847 construct on chromosome 2 were viable (Figure 2B, panel i), suggesting that lethality of CG1847 $7^{\text {exon1 } 3}$ flies is indeed due to loss of CG1847. The degree of rescue was determined by analysing the proportion of each viable male genotype in the second generation (Figure 2C). All offspring without endogenous CG1847 or without the rescue construct (Figure 2B, panel iii) died at the larval stage. However, a small number of males without the rescue construct, but phenotypically similar to males in Figure 2B, panel iii, were viable due to a meiotic non-disjunction event in the previous generation, a low-frequency phenomenon common in Drosophila genetics (online supplementary material 1, figures $1-3$ ). ${ }^{30-33}$

\section{Human AIP is able to functionally compensate for CG1847 loss}

Since CG1847-deficient males die at an early larval stage, they could serve as a useful model to test the functional conservation between human and Drosophila AIP. We used the UAS-GAL4 system to express a human AIP (UAS-hAIP) transgene under the control of a ubiquitously active promoter (actin-Gal4) and 
A
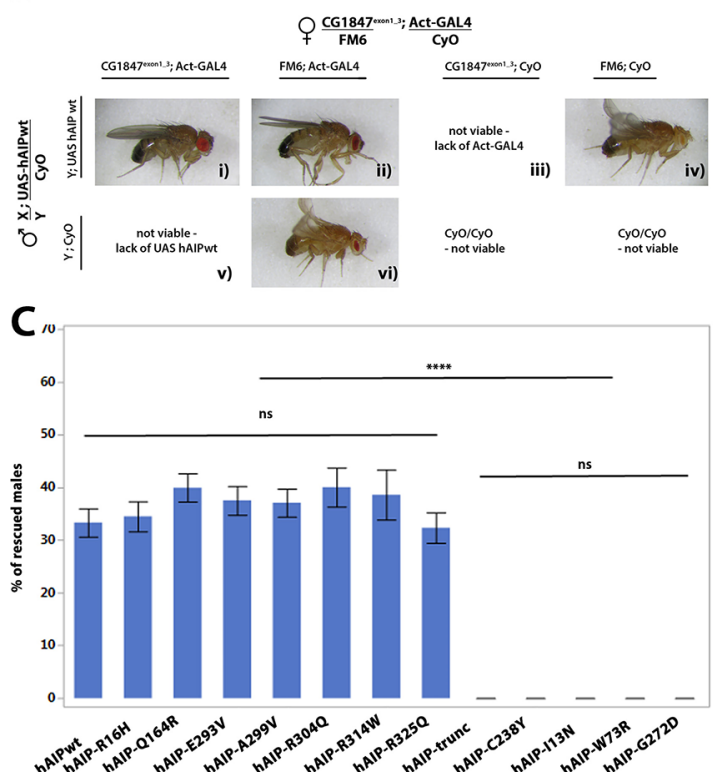

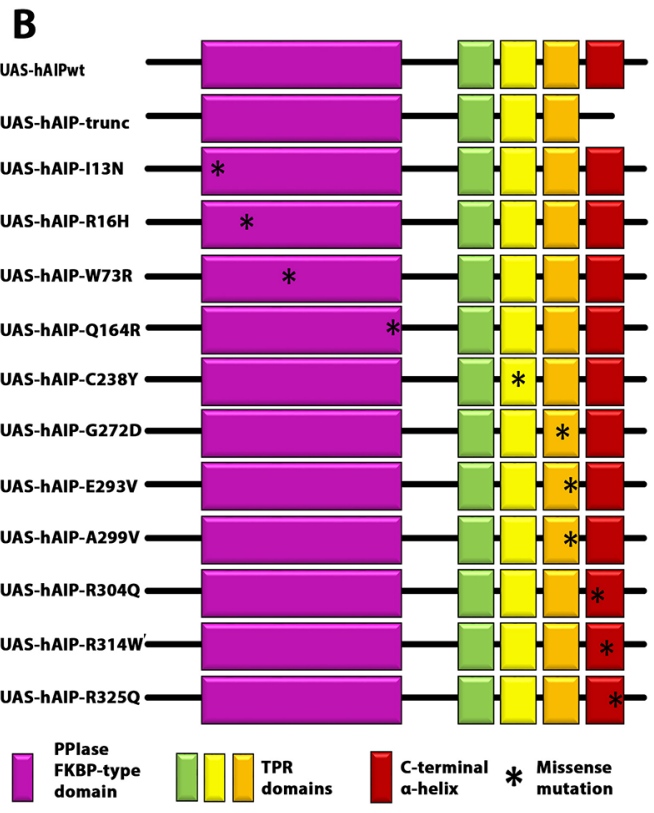

Figure 3 Human AIP functionally complements the Drosophila orthologue. (A) Transgenic males with hAIP rescue construct were crossed to heterozygous CG1847 deficient females. The ubiquitous actin-Ga/4 driver was used to drive the expression of the UAS-hAIP constructs during fly development. Panel (i) Images of F1 viable rescued males. Males expressing wt hAIP in the CG1847 mutant background (mutant CG1847 allele inherited from their maternal $X$ chromosome and expression of the hAIP transgene on chromosome 2); panels (iii) and (v): males inheriting the mutant CG1847 allele and lacking hAIP expression are not viable. These two genotypes also serve as internal negative controls. Panels (ii) and (iv): males lacking the CG1847 mutation are viable. (B) Schematic diagram of UAS-hAIP constructs. Top, wt UAS-hAIP. Second line: artificially generated truncated hAIP lacking the seventh alpha helix. Transgenic lines for 11 different hAIP missense mutations (p.R16H, p.C238Y, p.A299V, p.R304Q, p.I13N, p.W73R, p.Q164R, p.G272D, p.E293V, p.R314W and p.R325Q) were also generated. The approximate position of amino acid changes introduced are indicated with an asterisk. Protein domains are indicated by the colour code shown below the deletion construct assembly (the colours of the domains match what is shown in the 3D model, Figure 1). (C) Quantitative analysis of in vivo rescue experiments using hAIP missense variants $(n=6)$. Successful rescue of lethality was scored as the presence of males with the genotype CG1847200n1_3/Y; actin-Ga/4/UAS-hAIP, which lacks endogenous CG1847. Error bars represent SE of the mean. Significant differences are indicated by asterisks ( $\left.{ }^{* * *} \mathrm{P}<0.0001\right)$. AIP, aryl hydrocarbon receptor-interacting protein gene; TPR, tetratricopeptide repeat; wt, wild type.

assessed its ability to rescue the lethality of CG1847 mutant males. Ubiquitous expression of UAS-hAIP-wt was able to functionally replace CG1847 and rescue the lethality of Drosophila CG1847 exon1_3 $^{3}$ mutants (Figure 3A), confirming that AIP is functionally conserved between flies and humans. Moreover, the proportion of viable $\mathrm{F} 1$ males carrying the rescue $\mathrm{h} A I P$ construct was close to the expected proportion (33\% observed vs $25 \%$ expected in case of full rescue, corresponding to 1 of 4 viable genotypes). Flies expressing the UAS-hAIP-wt construct could therefore be used as a positive control for testing hAIP variants with unknown significance identified in patients with pituitary adenomas. We also generated transgenic flies with a hAIP construct containing a truncation mutation of the last $\alpha$-helix of the AIP protein - known to be crucial for AIP function ${ }^{2634}$ and used this as a positive (pathogenic) control representing a non-functional AIP protein (Figure $3 \mathrm{~B}$ ). This truncated hAIP was unable to rescue the CG1847 exon1_3 $^{3}$ mutant as no viable males were found expressing the truncated hAIP variant (Figure 3C).

\section{Human AIP missense variants differ in their ability to rescue CG1847 insufficiency}

Having demonstrated that wt hAIP expression in CG1847 knockout flies is able to rescue male lethality, while a truncated version is not, we next tested the rescue ability of 11 hAIP missense variants (p.I13N, p.R16H, p.W73R, p.Q164R, p.C238Y, p.G272D, p.E293V, p.A299V, p.R304Q, p.R314W and p.R325Q), found as germline variants in patients with pituitary adenomas (Figure 3B).
Out of all these tested variants, we selected one known to be a relatively common polymorphism (p.R16H) as a negative control, and two variants, a truncation mutation and the p.C238Y missense pathogenic mutation, as positive controls. There are considerable amount of data showing that p.R16H is a benign variant; it does not segregate with the disease ${ }^{35}$ and various in silico predictions and functional studies (online supplementary material 2) suggest that it is a benign polymorphism. ${ }^{36}$ Truncating variants are known to be pathogenic, while the p.C238Y missense variant is also known to be pathogenic, based on segregation, in silico testing, in vitro functional studies (cell proliferation ${ }^{13}$ and the PDE4A5 binding assays ${ }^{16}$ ) and halflife data ${ }^{4}$ (online supplementary material 2).

Given that all transgenes were site-specifically integrated into the genome, they are predicted to be expressed at similar levels. Clinical and genetic data available for these missense variants are presented in online supplementary material 2 .

For each missense variant, we compared the proportion of rescued males with the corresponding proportion obtained with the wt and truncated hAIP controls (Figure 3C). hAIP variants separated into two groups: the p.R16H, p.Q164R, p.E293V, p.A299V, p.R304Q, p.R314W and p.R325Q variants rescued the lethal CG1847 $7^{\text {exon1_}}{ }^{3}$ phenotype at a similar rate as wt hAIP (Figure 3C). In contrast, four missense variants (p.C238Y, p.I13N, p.W73R and p.G272D) were unable to rescue the male lethality of CG1847 mutants $(\mathrm{P}=0.0001)$ similar to the truncated AIP variant. The data obtained using our in vivo model supports and strengthens the clinical and bioinformatics data 


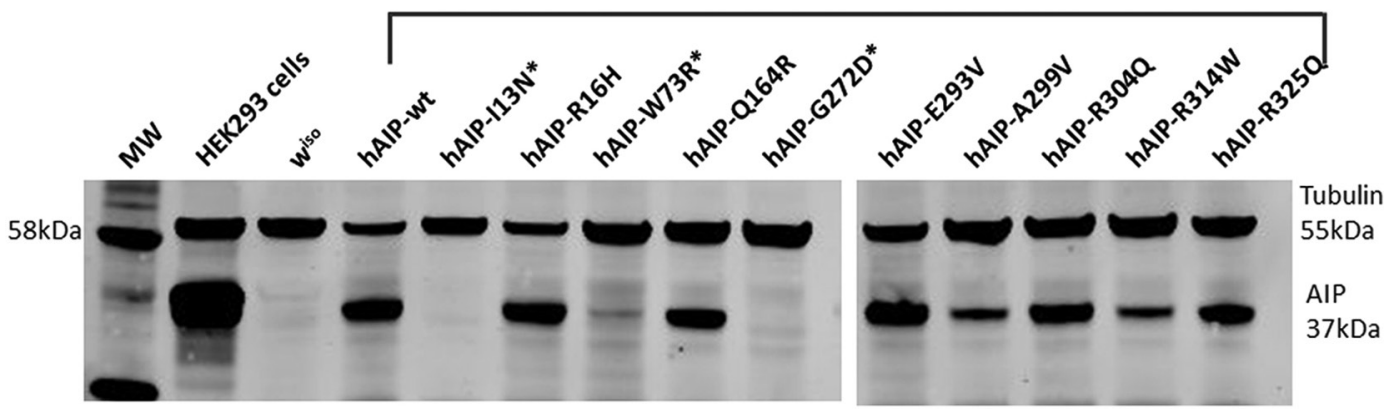

Figure 4 The different AIP constructs, wild-type human AIP (hAIP-wt) and various missense variants, show equivalent expression levels when ubiquitously expressed using the actin-Gal4 driver. CG1487 protein expression was not detected in wild-type flies $\left(w^{\text {iso }}\right)$, suggesting the anti-AIP antibody is specific for the human protein and does not recognise endogenous CG1487. $\beta$-tubulin was used as loading. Surviving males I13N*, W73R* and G272D* are viable as they have endogenous CG1487 but no hAIP due to non-disjunction (further details of the non-disjunction phenomenon is presented in online supplementary material 1). AlP, aryl hydrocarbon receptor-interacting protein gene.

indicating that p.C238Y, p.I13N, p.W73R and p.G272D AIP variants are pathogenic. However, our findings suggest that the p.R16H, p.Q164R, p.E293V, p.A299V, p.R304Q, p.R314W and p.R325Q variants are functionally normal sequence alterations in our experimental setting.

\section{$\mathrm{h} A I P$ rescue constructs have equivalent expression levels}

As ubiquitous expression of wt, p.R16H, p.Q164R, p.E293V, p.A299V, p.R304Q, p.R314W and p.R325Q hAIP resulted in rescue of $C G 1847^{\text {exon1_3 }}$ mutant males, total protein was extracted from fly heads to perform western blot analysis. Analysis of hAIP protein in fly lysates revealed a $37 \mathrm{kDa}$ band, equivalent to the band detected in human HEK293T cells used as positive control (figure 4). The various hAIP constructs show similar protein expression levels (figure 4$)$. Normal flies $\left(w^{\text {iso }}\right)$ were used as a negative control to confirm that the AIP antibody we used does not detect the endogenous CG1847 protein. In addition, transgenic males carrying the UAS-hAIP constructs only, without a Gal4 driver, did not display a hAIP band, excluding any detectable 'leakiness' of the transgenic UAS constructs (online supplementary figure 5).

While the p.R16H, p.Q164R, p.E293V, p.A299V, p.R304Q, p.R314W and p.R325Q hAIP missense constructs were able to rescue male lethality and displayed robust AIP expression (figure 4) similar to the level of wt hAIP, lysates from non-disjunction males (resulting from crosses with females carrying the p.I13N, p.W73R or p.G272D transgenes, figure 4, marked as *) did not contain human AIP protein. This confirmed that these males are indeed resulted from a non-disjunction event and are viable due to a normal copy of CG1847 (online supplementary figure 4).

\section{DISCUSSION}

Patients with loss-of-function AIP mutations suffer from pituitary adenomas. For missense variants, the assessment of the functional and physiological consequences is hampered by the lack of robust in vitro and in vivo assays. In the era of increasing sequence data on human subjects, one of the most challenging issues is distinguishing pathogenic from non-pathogenic variants. In this study, combining a knockout for CG1847 with the Gal4/UAS binary expression system, we developed and optimised an in vivo system to 'bioassay' the pathogenicity of AIP variants found in patients with pituitary tumours. ${ }^{37}$

We have found that deletion of the CG1847 results in lethality, similarly to AIP knockout mouse models, ${ }^{28} 29$ and re-introduction of CG1847 rescued this phenotype, demonstrating the specificity of our KO model. We then exploited the experimental power of Drosophila genetics to evaluate the degree of functional conservation between human AIP and its fly orthologue by testing whether CG1847 $7^{\text {exon } 13}{ }^{3}$ mutant flies could be rescued by human AIP.

A study of 287 human disease genes found a total of 178 (62\%) genes having likely homologues in Drosophila. ${ }^{38}$ Alignment of the human and fruit fly AIP proteins shows almost $40 \%$ identity, similar to the average level of protein identity between Drosophila and mammals. ${ }^{39}$

As the human gene was able to functionally compensate for the deletion of the Drosophila orthologue, our data support the evolutionary conservation of AIP gene function.

Furthermore, we have examined the effects of AIP variants in our Drosophila model in order to determine their pathogenicity. If a specific AIP variant rescues the lethality phenotype

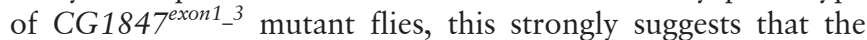
variant does not cause a major disruption of AIP function, at least with regard to Drosophila development. Conversely, failure to rescue the lethality phenotype indicates the variant is likely to be non-functional and could account for the human disease.

We investigated 11 AIP missense mutations identified in patients with pituitary adenoma. Summary of these mutations are listed in table 1 and further detailed in online supplementary material, part 1 . Our negative and positive controls confirmed the validity of the assay; $\mathrm{p} . \mathrm{R} 16 \mathrm{H}$ rescued the lethality to a level similar to wt AIP, while the truncated and p.C238Y variants failed to do so.

The lethality of CG1847 $7^{\text {exon1_3 }}$ mutants was rescued by 7 of the 11 tested hAIP missense variants (p.R16H, p.Q164R, p.E293V, p.A299V, p.304Q, p.R314W and p.R325Q), while four variants (p.C238Y, p.I13N, p.W73R and p.G272D) failed to do so. These data suggest that the latter four variants have a significant functional impairment or are unstable ${ }^{4}$ and therefore could represent pathogenic variants (see further discussion on these variants in online supplementary material 2). A similar strategy has previously been used to understand the conservation, functional role or importance of specific protein domains in human and Drosophila orthologues ${ }^{40-43}$ and could be employed to support clinical decision making.

Determining whether a variant is a disease-causing one is a significant challenge in the management of patients carrying a missense AIP variant, ${ }^{8}$ or indeed in any other partially penetrant disease. ${ }^{36}$ Evaluation of variant segregation with the phenotype 
Table 1 Characterisation of AIP missense mutations identified in the various patients and investigated in this study

\begin{tabular}{|c|c|c|c|c|c|c|}
\hline Variant & MAF in GnomAD & $\begin{array}{l}\text { Typical phenotype } \\
\text { (young, growth hormone (GH)-secreting } \\
\text { adenoma) }\end{array}$ & LOH & Functional data & In silico prediction & $\begin{array}{l}\text { Drosophila } \\
\text { rescued }\end{array}$ \\
\hline c. $38 \mathrm{~T}>\mathrm{A}, \mathrm{p} .113 \mathrm{~N}$ & $8.25 \mathrm{E}-06$ & Young, GH-secreting adenoma & Yes & Not studied & Probably damaging & No \\
\hline c. $47 \mathrm{G}>\mathrm{A}, \mathrm{p} . \mathrm{R} 16 \mathrm{H}$ & 0.001956 & Familial cases, GH-secreting adenoma & No & Non-pathogenic & Probably damaging & Yes \\
\hline c.217T>C, p.W73R & 0 & Young, GH-secreting adenoma & Not studied & Not studied & Probably damaging & No \\
\hline c.491A>G, p.Q164R & 0 & Young, GH-secreting adenoma & Not studied & Not studied & Benign & Yes \\
\hline c. $713 \mathrm{G}>\mathrm{A}$, p.C238Y & $8.42 \mathrm{E}-06$ & Familial cases, GH-secreting adenoma & Yes & Pathogenic & Probably damaging & No \\
\hline c. $815 G>A, p . G 272 D$ & 0 & Elderly, GH-secreting adenoma & Not studied & Not studied & Probably damaging & No \\
\hline c.878A $>$ T, p.E293V & 0 & Elderly, GH-secreting adenoma & Not studied & Not studied & Benign & Yes \\
\hline c. $896 \mathrm{C}>\mathrm{T}, \mathrm{p} . \mathrm{A} 299 \mathrm{~V}$ & $4.00 \mathrm{E}-04$ & No & Not studied & Non-pathogenic & Benign & Yes \\
\hline c. $911 \mathrm{G}>\mathrm{A}, \mathrm{p} . \mathrm{R} 304 \mathrm{Q}$ & 0.001458 & Multiple cases & No & Non-pathogenic & Benign & Yes \\
\hline c. $940 \mathrm{C}>\mathrm{T}, \mathrm{p} . \mathrm{R} 314 \mathrm{~W}$ & $4.03 \mathrm{E}-05$ & Young, GH-secreting adenoma & Not studied & Not studied & Probably damaging & Yes \\
\hline c. $974 G>A, p . R 325 Q$ & 0.000058 & Young, prolactin-secreting adenoma & Yes & Non-pathogenic & Benign & Yes \\
\hline
\end{tabular}

AIP, aryl hydrocarbon receptor-interacting protein gene; $\mathrm{MAF}$, minor allele frequency.

in large pedigrees is the initial approach for investigating rare mutations. ${ }^{10}$ However, in case of AIP variants, this method is less practical due to the incomplete penetrance of the disease and the rarity of large families. Currently, there is no single method that can invariably predict the correct American College of Medical Genetics and Genomics (ACMG) category ('pathogenic', 'likely pathogenic', 'uncertain significance', 'likely benign' and 'benign’) for missense variants. Although in silico prediction pipelines are often used, their results are not reliable, as shown recently, for endocrine genes including $A I P .^{36}$ In addition to clinical data, such as segregation and variant frequency in the general population, various in vitro and in vivo methods could be used to help in the decision making. Inevitably, all methods have pitfalls. In vitro studies may not accurately recreate the environment present in a living organism. In the case of missense mutations, the change in amino acid sequence could disrupt their tertiary structure, with consequences for folding, stability and availability of protein-protein interaction sites. Robust and repeatable functional studies performed in clinical laboratories, however, have a significant role according to the ACMG guidelines. ${ }^{44}$

It was previously shown that the intact amino acid sequence of the TPR domains of AIP is essential for a proper interaction among amino acid residues in neighbouring alpha helices ${ }^{5}$; if these amino acids are changed by missense mutations, the resulted misfolded proteins are usually unstable. ${ }^{6}$ Various in vitro studies were employed to evaluate AIP variants, such as $\mathrm{LOH}$ analysis, splicing assays, cell proliferation, PDE4A5 binding and protein turnover. ${ }^{413} 1645$ As we do not fully understand the mechanism of tumourigenesis induced by lack of AIP, the assay we might use in in vitro studies may not represent the true function of AIP. We demonstrated that AIP is an essential gene and several functional and comparative genomic analyses confirmed that essential genes are conserved during evolution. ${ }^{46-49}$ The fact that AIP is highly conserved among the species supports the fact that it is a disease-associated protein. ${ }^{50}$ As signalling pathways involved in organ development, cell proliferation, cell survival and cell migration are highly conserved in D. melanogaster, ${ }^{51} 52$ the results of fruit fly studies were shown to be transferable to humans; more than half of the known human disease genes, have homologues in fruit fly. ${ }^{53}$ We employed a Drosophila model organism to discover the conserved role of AIP and to avoid potential confounding factors arising from the redundancy and variability that can be generated by the analysis of more complex organisms. However, in vivo experiments, such as our Drosophila bioassay, may not correctly predict the functionality of a variant.
Mouse studies, although closer to humans than Drosophila, can also provide misleading conclusions in some diseases. ${ }^{54}$ However, the fact that we used the human AIP protein in our studies and that this was sufficient to rescue the developmental function of the Drosophila orthologue is potentially a major advantage of our in vivo system, and this could be an additional approach to help clinicians reach the right conclusion.

In summary, we have engineered an in vivo bioassay for characterising patient-based AIP variants. The data presented support the evolutionary conservation of the AIP gene. Deletions of the endogenous Drosophila orthologue resulted in lethality of the flies, while the human gene can compensate for this loss. Rescue patterns of missense AIP variants can complement clinical and bioinformatics data and inform clinical decision making regarding AIP variants. ${ }^{816}$ The benefit of cascade genetic screening and clinical follow-up has already been established in AIP mutation-positive families, ${ }^{355} 56$ while family members in kindreds with non-pathogenic variants could be spared the psychological and financial burden of genetic testing and clinical follow-up.

Acknowledgements We would like to thank to Professor Nick Brown (Department of Physiology, Development and Neuroscience, University of Cambridge) and Nic Tapon, Cancer Research UK for support regarding fly stocks and useful comments on the project. We are grateful for Professor Ashley Grossman for the careful reading of the manuscript. Fruit fly stocks obtained from the Bloomington Drosophila Stock Center (NIH P40OD018537). The authors would like to thank the ExomeAggregation Consortium and the groups that provided exome variant data for comparison. A full list of contributing groups can be found at http://exac. broadinstitute.org about. The SNP annotations and genome location are accordingly Human Feb. 2009 (GRCh37/hg19) Assembly, Genome Browser website (http:// genome.ucsc.edu). ${ }^{5}$

Contributors EDA and MK prepared the manuscript for publication, in consultation with PSR and RS. All other authors had a role in contributing intellectually to redrafting the manuscript. All experiments were performed by EDA with support from BK, CC, NM and AND. SR supported the statistical analysis and assisted with drafting the manuscript. CP created the CG1847 protein theoretical model. All authors have seen and approved the final manuscript.

Funding Grant number MR/M018539/1 granted by Medical Research Council; WS733753 granted by Pfizer UK, November 2014 Early Career Grant awarded by Society for Endocrinology; \#2011-5 awarded by William Harvey Research Foundation.

Competing interests None declared.

Patient consent Not required.

Provenance and peer review Not commissioned; externally peer reviewed.

Data sharing statement Not required as no additional unpublished data from the study.

Open access This is an open access article distributed in accordance with the terms of the Creative Commons Attribution (CC BY 4.0) license, which permits others 
to distribute, remix, adapt and build upon this work, for commercial use, provided the original work is properly cited. See: http://creativecommons.org/licenses/by/4.0/ (c) Article author(s) (or their employer(s) unless otherwise stated in the text of the article) 2018. All rights reserved. No commercial use is permitted unless otherwise expressly granted.

\section{REFERENCES}

1 Vierimaa O, Georgitsi M, Lehtonen R, Vahteristo P, Kokko A, Raitila A, Tuppurainen K, Ebeling TM, Salmela PI, Paschke R, Gündogdu S, De Menis E, Mäkinen MJ, Launonen $V$, Karhu A, Aaltonen LA. Pituitary adenoma predisposition caused by germline mutations in the AIP gene. Science 2006:312:1228-30.

2 Beckers A, Aaltonen LA, Daly AF, Karhu A. Familial isolated pituitary adenomas (FIPA) and the pituitary adenoma predisposition due to mutations in the aryl hydrocarbon receptor interacting protein (AIP) gene. Endocr Rev 2013;34:239-77.

3 Hernández-Ramírez LC, Gabrovska P, Dénes J, Stals K, Trivellin G, Tilley D, Ferrau F, Evanson J, Ellard S, Grossman AB, Roncaroli F, Gadelha MR, Korbonits M. International FIPA Consortium. Landscape of Familial Isolated and Young-Onset Pituitary Adenomas: Prospective Diagnosis in AIP Mutation Carriers. J Clin Endocrinol Metab 2015; 100:E1242-54

4 Hernández-Ramírez LC, Martucci F, Morgan RM, Trivellin G, Tilley D, Ramos-Guajardo N, lacovazzo D, D'Acquisto F, Prodromou C, Korbonits M. Rapid Proteasomal Degradation of Mutant Proteins Is the Primary Mechanism Leading to Tumorigenesis in Patients With Missense AIP Mutations. J Clin Endocrinol Metab 2016;101:3144-54.

5 D'Andrea LD, Regan L. TPR proteins: the versatile helix. Trends Biochem Sci 2003;28:655-62.

6 Kamburov A, Lawrence MS, Polak P, Leshchiner I, Lage K, Golub TR, Lander ES, Getz $\mathrm{G}$. Comprehensive assessment of cancer missense mutation clustering in protein structures. Proc Natl Acad Sci U S A 2015;112:E5486-95.

7 Das AK, Cohen PW, Barford D. The structure of the tetratricopeptide repeats of protein phosphatase 5: implications for TPR-mediated protein-protein interactions. Embo J 1998:17:1192-9.

8 Korbonits M, Storr H, Kumar AV. Familial pituitary adenomas - who should be tested for AlP mutations? Clin Endocrinol 2012;77:351-6.

9 Thusberg J, Olatubosun A, Vihinen M. Performance of mutation pathogenicity prediction methods on missense variants. Hum Mutat 2011;32:358-68.

10 MacArthur DG, Manolio TA, Dimmock DP, Rehm HL, Shendure J, Abecasis GR, Adams DR, Altman RB, Antonarakis SE, Ashley EA, Barrett JC, Biesecker LG, Conrad DF, Cooper GM, Cox NJ, Daly MJ, Gerstein MB, Goldstein DB, Hirschhorn JN, Leal SM, Pennacchio LA, Stamatoyannopoulos JA, Sunyaev SR, Valle D, Voight BF, Winckler W, Gunter $C$. Guidelines for investigating causality of sequence variants in human disease. Nature 2014;508:469-76.

11 Salvatori R, Daly AF, Quinones-Hinojosa A, Thiry A, Beckers A. A clinically novel AIP mutation in a patient with a very large, apparently sporadic somatotrope adenoma. Endocrinol Diabetes Metab Case Rep 2014;2014:140048.

12 Iwata T, Yamada S, Mizusawa N, Golam HM, Sano T, Yoshimoto K. The aryl hydrocarbon receptor-interacting protein gene is rarely mutated in sporadic $\mathrm{GH}$ secreting adenomas. Clin Endocrinol 2007;66:070115055241005-502.

13 Leontiou CA, Gueorguiev M, van der Spuy J, Quinton R, Lolli F, Hassan S, Chahal HS, Igreja SC, Jordan S, Rowe J, Stolbrink M, Christian HC, Wray J, Bishop-Bailey D, Berney DM, Wass JA, Popovic V, Ribeiro-Oliveira A, Gadelha MR, Monson JP, Akker SA, Davis JR, Clayton RN, Yoshimoto K, Iwata T, Matsuno A, Eguchi K, Musat M, Flanagan D, Peters G, Bolger GB, Chapple JP, Frohman LA, Grossman AB, Korbonits M. The role of the aryl hydrocarbon receptor-interacting protein gene in familial and sporadic pituitary adenomas. J Clin Endocrinol Metab 2008;93:2390-401.

14 Daly AF, Tichomirowa MA, Petrossians P, Heliövaara E, Jaffrain-Rea ML, Barlier A, Naves LA, Ebeling T, Karhu A, Raappana A, Cazabat L, De Menis E, Montañana CF, Raverot G, Weil RJ, Sane T, Maiter D, Neggers S, Yaneva M, Tabarin A, Verrua E, Eloranta E, Murat A, Vierimaa O, Salmela PI, Emy P, Toledo RA, Sabaté MI, Villa C, Popelier M, Salvatori R, Jennings J, Longás AF, Labarta Aizpún Jl, Georgitsi M, Paschke R, Ronchi C, Valimaki M, Saloranta C, De Herder W, Cozzi R, Guitelman M, Magri F, Lagonigro MS, Halaby G, Corman V, Hagelstein MT, Vanbellinghen JF, Barra GB, Gimenez-Roqueplo AP, Cameron FJ, Borson-Chazot F, Holdaway I, Toledo SP, Stalla GK, Spada A, Zacharieva S, Bertherat J, Brue T, Bours V, Chanson P, Aaltonen LA, Beckers A. Clinical characteristics and therapeutic responses in patients with germ-line AIP mutations and pituitary adenomas: an international collaborative study. J Clin Endocrinol Metab 2010;95:E373-83.

15 Jaffrain-Rea ML, Angelini M, Gargano D, Tichomirowa MA, Daly AF, Vanbellinghen JF, D'Innocenzo E, Barlier A, Giangaspero F, Esposito V, Ventura L, Arcella A, Theodoropoulou M, Naves LA, Fajardo C, Zacharieva S, Rohmer V, Brue T, Gulino A, Cantore G, Alesse E, Beckers A. Expression of aryl hydrocarbon receptor (AHR) and AHR-interacting protein in pituitary adenomas: pathological and clinical implications. Endocr Relat Cancer 2009;16:1029-43.

16 Igreja S, Chahal HS, King P, Bolger GB, Srirangalingam U, Guasti L, Chapple JP, Trivellin G, Gueorguiev M, Guegan K, Stals K, Khoo B, Kumar AV, Ellard S, Grossman AB, Korbonits M. International FIPA Consortium. Characterization of aryl hydrocarbon receptor interacting protein (AIP) mutations in familial isolated pituitary adenoma families. Hum Mutat 2010;31:950-60.
17 Vargiolu M, Fusco D, Kurelac I, Dirnberger D, Baumeister R, Morra I, Melcarne A, Rimondini R, Romeo G, Bonora E. The tyrosine kinase receptor RET interacts in vivo with aryl hydrocarbon receptor-interacting protein to alter survivin availability. J Clin Endocrinol Metab 2009:94:2571-8.

18 Lindsley DL, Zimm GG. The Genome of Drosophila melanogaster. San Diego: California Academic Press, 1992.

19 Luo L, Liao YJ, Jan LY, Jan YN. Distinct morphogenetic functions of similar small GTPases: Drosophila Drac1 is involved in axonal outgrowth and myoblast fusion. Genes Dev 1994;8:1787-802.

20 Bellen HJ, Levis RW, He Y, Carlson JW, Evans-Holm M, Bae E, Kim J, Metaxakis A, Savakis C, Schulze KL, Hoskins RA, Spradling AC. The Drosophila gene disruption project: progress using transposons with distinctive site specificities. Genetics 2011;188:731-43.

21 Kasuki Jomori de Pinho L, Vieira Neto L, Armondi Wildemberg LE, Gasparetto EL, Marcondes J, de Almeida Nunes B, Takiya CM, Gadelha MR. Low aryl hydrocarbon receptor-interacting protein expression is a better marker of invasiveness in somatotropinomas than Ki-67 and p53. Neuroendocrinology 2011;94:39-48.

22 Chu DT, Klymkowsky MW. The appearance of acetylated alpha-tubulin during early development and cellular differentiation in Xenopus. Dev Biol 1989;136:104-17.

23 Pruitt KD, Tatusova T, Maglott DR. NCBI Reference Sequence (RefSeq): a curated nonredundant sequence database of genomes, transcripts and proteins. Nucleic Acids Res 2005;33:D501-4.

24 Sievers F, Wilm A, Dineen D, Gibson TJ, Karplus K, Li W, Lopez R, McWilliam H, Remmert M, Söding J, Thompson JD, Higgins DG. Fast, scalable generation of highquality protein multiple sequence alignments using Clustal Omega. Mol Syst Biol 2011;7:539.

25 Linnert M, Lin YJ, Manns A, Haupt K, Paschke AK, Fischer G, Weiwad M, Lücke C. The FKBP-type domain of the human aryl hydrocarbon receptor-interacting protein reveals an unusual Hsp90 interaction. Biochemistry 2013;52:2097-107.

26 Morgan RM, Hernández-Ramírez LC, Trivellin G, Zhou L, Roe SM, Korbonits M, Prodromou C. Structure of the TPR domain of AIP: lack of client protein interaction with the C-terminal $\alpha-7$ helix of the TPR domain of AIP is sufficient for pituitary adenoma predisposition. PLoS One 2012;7:e53339.

27 Witsell A, Kane DP, Rubin S, McVey M. Removal of the bloom syndrome DNA helicase extends the utility of imprecise transposon excision for making null mutations in Drosophila. Genetics 2009;183:1187-93.

28 Lin BC, Nguyen LP, Walisser JA, Bradfield CA. A hypomorphic allele of aryl hydrocarbon receptor-associated protein-9 produces a phenocopy of the AHR-null mouse. $\mathrm{Mol}$ Pharmacol 2008;74:1367-71.

29 Lin BC, Sullivan R, Lee Y, Moran S, Glover E, Bradfield CA. Deletion of the aryl hydrocarbon receptor-associated protein 9 leads to cardiac malformation and embryonic lethality. J Biol Chem 2007;282:35924-32.

30 Cooper KW. A New Theory of Secondary Non-Disjunction in Female Drosophila Melanogaster. Proc Natl Acad Sci U S A 1948;34:179-87.

31 Bridges CB. Non-disjunction as proof of the chromosome theory of heredity. Genetics 1916:1:1-52.

32 Sturtevant $A H$, Beadle GW. The relations of inversions in the $X$ chromosome of drosophila melanogaster to crossing over and disjunction. Genetics 1936;21:554-604.

33 O'Tousa J. Meiotic chromosome behavior influenced by mutation-altered disjunction in Drosophila melanogaster females. Genetics 1982;102:503-24.

34 Kazlauskas A, Poellinger L, Pongratz I. Two distinct regions of the immunophilin-like protein XAP2 regulate dioxin receptor function and interaction with hsp90. J Biol Chem 2002;277:11795-801.

35 Guaraldi F, Salvatori R. Familial isolated pituitary adenomas: from genetics to therapy. Clin Trans/ Sci 2011;4:55-62.

36 Newey PJ, Berg JN, Zhou K, Palmer CNA, Thakker RV. Utility of Population-Level DNA Sequence Data in the Diagnosis of Hereditary Endocrine Disease. J Endocr Soc 2017:1:1507-26.

37 Groth AC, Fish M, Nusse R, Calos MP. Construction of transgenic Drosophila by using the site-specific integrase from phage phiC31. Genetics 2004;166:1775-82.

38 Fortini ME, Skupski MP, Boguski MS, Hariharan IK. A survey of human disease gene counterparts in the Drosophila genome. J Cell Biol 2000;150:F23-30.

39 Pandey UB, Nichols CD. Human disease models in Drosophila melanogaster and the role of the fly in therapeutic drug discovery. Pharmacol Rev 2011;63:411-36.

40 Grossman TR, Gamliel A, Wessells RJ, Taghli-Lamallem O, Jepsen K, Ocorr K, Korenberg JR, Peterson KL, Rosenfeld MG, Bodmer R, Bier E. Over-expression of DSCAM and COL6A2 cooperatively generates congenital heart defects. PLoS Genet 2011:7:e1002344.

41 Ikmi A, Gaertner B, Seidel C, Srivastava M, Zeitlinger J, Gibson MC. Molecular evolution of the Yap/Yorkie proto-oncogene and elucidation of its core transcriptional program. Mol Biol Evol 2014;31:1375-90.

42 Kudumala S, Freund J, Hortsch M, Godenschwege TA. Differential effects of human L1CAM mutations on complementing guidance and synaptic defects in Drosophila melanogaster. PLoS One 2013;8:e76974.

43 D'Brot A, Kurtz P, Regan E, Jakubowski B, Abrams JM. A platform for interrogating cancer-associated p53 alleles. Oncogene 2017;36:286-91. 
44 Richards S, Aziz N, Bale S, Bick D, Das S, Gastier-Foster J, Grody WW, Hegde M, Lyon E, Spector E, Voelkerding K, Rehm HL, Committee A; ACMG Laboratory Quality Assurance Committee. Standards and guidelines for the interpretation of sequence variants: a joint consensus recommendation of the American College of Medical Genetics and Genomics and the Association for Molecular Pathology. Genet Med 2015;17:405-24.

45 Denes J, Swords FM, Xekouki P, Kumar AV, Maher ER, Ferscht N, Grieve J, Baldeweg SE, Stratakis CA, Korbonits M. Familial pituitary adenoma and paraganglioma syndrome - A novel type of multiple endocrine neoplasia. Endocr Rev 2012;33:OR41-2.

46 Bergmiller T, Ackermann M, Silander OK. Patterns of evolutionary conservation of essential genes correlate with their compensability. PLoS Genet 2012;8:e1002803.

47 Rocha EP, Danchin A. An analysis of determinants of amino acids substitution rates in bacterial proteins. Mol Biol Evol 2004;21:108-16.

48 Gerdes SY, Scholle MD, Campbell JW, Balázsi G, Ravasz E, Daugherty MD, Somera AL, Kyrpides NC, Anderson I, Gelfand MS, Bhattacharya A, Kapatral V, D'Souza M, Baev MV, Grechkin Y, Mseeh F, Fonstein MY, Overbeek R, Barabási AL, Oltvai ZN, Osterman AL. Experimental determination and system level analysis of essential genes in Escherichia coli MG1655. J Bacteriol 2003;185:5673-84.

49 Jordan IK, Rogozin IB, Wolf YI, Koonin EV. Essential genes are more evolutionarily conserved than are nonessential genes in bacteria. Genome Res 2002;12:962-8.

50 Lovell SC, Li X, Weerasinghe NR, Hentges KE. Correlation of microsynteny conservation and disease gene distribution in mammalian genomes. BMC Genomics 2009; 10:521.
51 Arbouzova NI, Zeidler MP. JAK/STAT signalling in Drosophila: insights into conserved regulatory and cellular functions. Development 2006;133:2605-16.

52 Huangfu D, Anderson KV. Signaling from Smo to Ci/Gli: conservation and divergence of Hedgehog pathways from Drosophila to vertebrates. Development 2006;133:3-14.

53 St Johnston D. The art and design of genetic screens: Drosophila melanogaster. Nat Rev Genet 2002;3:176-88.

54 Elsea SH, Lucas RE. The mousetrap: what we can learn when the mouse model does not mimic the human disease. Ilar J 2002;43:66-79.

55 Williams F, Hunter S, Bradley L, Chahal HS, Storr HL, Akker SA, Kumar AV, Orme SM, Evanson J, Abid N, Morrison PJ, Korbonits M, Atkinson AB. Clinical experience in the screening and management of a large kindred with familial isolated pituitary adenoma due to an aryl hydrocarbon receptor interacting protein (AIP) mutation. J Clin Endocrinol Metab 2014;99:1122-31.

56 Chahal HS, Trivellin G, Leontiou CA, Alband N, Fowkes RC, Tahir A, Igreja SC, Chapple JP, Jordan S, Lupp A, Schulz S, Ansorge O, Karavitaki N, Carlsen E, Wass JA, Grossman AB, Korbonits M. Somatostatin analogs modulate AIP in somatotroph adenomas: the role of the ZAC1 pathway. J Clin Endocrinol Metab 2012;97:E1411-20.

57 Rosenbloom KR, Armstrong J, Barber GP, Casper J, Clawson H, Diekhans M, Dreszer TR, Fujita PA, Guruvadoo L, Haeussler M, Harte RA, Heitner S, Hickey G, Hinrichs AS, Hubley R, Karolchik D, Learned K, Lee BT, Li CH, Miga KH, Nguyen N, Paten B, Raney BJ, Smit AF, Speir ML, Zweig AS, Haussler D, Kuhn RM, Kent WJ. The UCSC Genome Browser database: 2015 update. Nucleic Acids Res 2015;43:D670-81. 